\title{
The Lives of Girls and Young Women in the Time of COVID-19
}

\author{
Claudia Mitchell and Ann Smith
}

\section{$\cos 80$}

As with Zika, Ebola, HIV and AIDS, and other pandemics in recent history, girls and young women are particularly vulnerable to COVID-19 socially and emotionally if not medically. Some observers have referred to the current crisis as a tale of two pandemics in reference to both the obvious health issues and the pervasive gender inequalities that have become exacerbated, and others have referred to it as "the shadow pandemic" (UN Women 2020: n.p.) in highlighting the negative impact that physical distancing and social isolation are having on already vulnerable girls and young women experiencing sex- and gender-based violence. All over the world girls and young women are facing increasing levels of precariousness as a direct result of the health measures being taken to curb the global transmission of COVID-19. The increasing lack of privacy in the home furthers the practice of cultural forms of patriarchy that lead to violence.

Local and international NGOs, government ministries, and researchers have been developing emergency responses during this time of physical distancing, but we must tread carefully and thoughtfully in our response to what has become the new normal. Working to combat sex- and gender-based violence could, at least potentially, do more harm than good as we work to uncover the experiences of girls and young women in situations of social isolation and lockdown. The high rates of intimate partner violence and child abuse behind closed doors means that face-to-face as well as remote technology-driven and text-based investigative programming carried out by researchers and NGOs are proving to be problematic. Another critical component in a time of physical distancing, lockdowns, and social isolation is that vulnerable girls and young women are unable to access support services like girls' clubs, gender clubs, hotlines, and supportive programming 
that might otherwise be in place. There is concern on the part of many international NGOs working on girls' education and on broader issues of gender equity that many of the gains over the last few years are already being lost. Clearly, the global dramatic economic downturn will affect financial support for many of the programs in place. There is also the worry that less progressive agendas will have a deleterious impact on programs supporting girls and young women.

The issues noted above were just some of the ideas that we raised when we put out a call for articles in May, 2020, for submissions to a special issue on the lives of girls and young women in the time of COVID-19. It was two months into the pandemic, schools had closed, people were living under lockdown conditions, and already alarm bells were sounding. It was with some apprehension that we issued the call, wondering about who would be able to do current empirical research, who would be available to write articles in this unprecedented time of lockdown and home schooling, who would have time and be available to review them, and would we have just enough articles for a special section only and not a whole issue. In the end, our fears turned out to be totally unfounded; we were inundated with proposals followed by full manuscripts in record time. Thanks to this, there is now this special issue and an edited collection, The Girl in the Pandemic, to be published by Berghahn, is in the works. This collection of articles we regard as remarkable, representing as it does the situation for girls and young women in a wide range of countries from both the Global North and the Global South (Russia, China, US, Canada, Jordan, Kenya, and Bangaladesh) that address a wide range of concerns including: the effects of homelessness on girls and on those left behind in rural areas when their parents seek urban work; intergenerational support in Indigenous communities; the difficulties of online education for transgirls; the effects on girls who are engaging in online dating and those choosing between normative COVID-19 behavior and rebellion against the rules; the effects on girls transitioning into adulthood in informal settlements in Africa and on displaced adolescent girls' experiences given their social isolation and lack of privacy; girls' efforts to negotiate motivation and to be productive along with young women university students' activist engagement with young girls. Contributors investigate these issues through an array of innovative methods and tools such as conducting interviews and doing participatory visual work on online platforms and even testing out new genres of representation such as a graphic story in comic book style and a visual novella. 
This special issue opens with articles based on research with girls and young women. In our lead article, "Russian Girls Construct Freedom and Safety in Pandemic Times," Olga Zdravomyslova and Elena Onegina in which they consider how ten girls aged between 15 and 19 "are dealing with the fundamentally new and dangerous situation created by the coronavirus pandemic." They focus on how some of these girls work towards safety and stability while others deny the need for the restrictions imposed by the Russian authorities. They conclude that these challenges fail to constrain the girls' "urge for agency and their desire to change their own situation."

Then Jue Wang, in "Left Behind by COVID-19: Experiences of "Left-Behind" Girls in Rural China" discusses how the education of five young girls, whose parents have left them behind in rural China in order to seek work in urban areas, is affected by the social isolation imposed by the COVID-19 pandemic. She found that this isolation "has exposed and magnified gender inequalities, particularly those related to the maltreatment exerted by their guardians and/or brothers" and the result is that that these girls and others like them have been left "even further behind."

We move then from Russia and China to the US. In "The Girlhood Project: Pivoting our Model with Girls During COVID-19” Cheryl Weiner, Kathryn Van Demark, Sarah Doyle, Jocelyn Martinez, Fia Walklet, and Amy Rutstein-Riley outline how "Girlhood, Identity and Girl Culture," an undergraduate course at Lesley University that "works with community partners to bring middle and high school girls to Lesley's campus ... as part of intergenerational girls' groups that are co-facilitated by Lesley students," adapted their model "to a virtual and synchronous platform for students during COVID-19 [that] supported their learning competencies."

In "Girls and Young Women Negotiate Wellbeing during COVID-19 in Quebec," Jennifer A. Thompson, Sarah L. Fraser, Rocio Macabena Perez, Charlotte Paquette, and Katherine L. Frohlich "feature photographs and cellphilms produced by 13 girls and young women (aged 13 to 19) from urban, rural, and Indigenous areas of Quebec, Canada, during the COVID-19 pandemic" along with the girls' and young women's "coanalysis about [their] wellbeing during a period of lockdown." They explore how these participants dealt with "the pressure to be productive" and how "they engaged with the politics of the pandemic and advocated for collective forms of wellbeing."

Alanna Goldstein and Sarah Flicker, in "Some Things Just Won't Go Back": Teen Girls' Online Dating Relationships during COVID-19” explore the "dating and relationship experiences during the early stages of 
the COVID-19 pandemic" of 25 teen girls in Canada in May and June 2020. Since many participants spoke about the "limitations and drawbacks of being able to connect only virtually" these authors suggest that we need to "attend to the impacts that COVID-19 restrictions are having on teen girls' dating relationships, as well as to the larger impacts that the deterioration of these relationships might be having on their mental and emotional health."

In her use of Comics Based Research, Sally Galman's graphic story, "Ghostly presences OUT THERE: Transgender Girls and Their Families in the Time of COVID" provides us with a bridge into the next sectionresearch on girls and young women. The online safety of Galman's protagonist, Lily, a 12-year-old transgirl is disrupted by the "borderless quality" of school being beamed into her bedroom and she experiences the anxiety and discomfort of this penetration of school into her safe space. Galman offers useful suggestions to ensure the wellbeing of transgirls and notes that "more research is needed to understand marginalized girls' experiences when things fall apart."

Reporting on research done in Bangladesh and Jordan, Sarah Baird, Sarah Alheiwidi, Rebecca Dutton, Khadija Mitu, Erin Oakley, Tassew Woldehanna, and Nicola Jones, in "Social Isolation and Disrupted Privacy: Impacts of COVID-19 on Adolescent Girls in Humanitarian Contexts" discuss how the COVID-19 pandemic lockdown "has shattered the everyday lives of young people" with potentially "long-term detrimental impacts." Using "rapid virtual quantitative and qualitative surveys undertaken with over 4,800 adolescents affected by displacement in Bangladesh and Jordan" these authors suggest that the pandemic has had a great impact on girls "particularly those with disabilities."

In "Kokums to the Iskwêsisisak: COVID-19 and Urban Métis Girls and Young Women," Carly Jones, Renée Monchalin, Cheryllee Bourgeois, and Janet Smylie "demonstrate that while Métis women and girls have been left out of the national pandemic response, they continue to carry intergenerational healing knowledges that have been passed down from the kokums (grandmas) to the iskwêsisisak (girls)." They describe the "innovative and community-based initiatives like Well Living House and the Call Auntie Hotline" to show how "urban Métis girls and women are both managing and tackling COVID-19."

Meghan Bellerose, Maryama Diaw, Jessie Pinchoff, Beth Kangwana, and Karen Austrian present, in "Pre-pandemic Influences on Kenyan Girls' Transitions to Adulthood during COVID-19," the findings of the Population Council on "phone-based surveys with 856 girls aged between 
10 and 19 in 5 informal settlements who had been surveyed prior to COVID-19 as part of two longitudinal studies." They found that food insecurity threatens younger girls who also experience difficulty coping with home learning during school closures, while many older girls who have forgone health services "face the immediate risk of dropping out of school permanently."

In "Girls, Homelessness, and COVID-19: The Urgent Need for Research and Action," Kaitlin Schwan, Erin Dej, and Alicia Versteegh contribute to the "limited gendered analysis of how COVID-19 has shaped girls' access to housing" in Canada and point out that the "socio-economic exclusion of girls who are homeless is likely to increase" in this country as a result of the pandemic. They discuss the effects of the feminization of poverty, the uneven burden of childcare, and gender-based violence on this exclusion and argue that research is needed to "address the structural conditions that foster pathways into homelessness for low-income and marginalized girls in the context of COVID-19 and beyond."

In a section of its own is Nasrin Siddiqa's visual essay, "Intersectional Pandemics in Bangladesh: The Effects of COVID-19 on Girls." In a series of pictures by the young artist Monon Mahfuz, Siddiqa shows how "girls and women are the first victims of any calamity, pandemic, or disaster in developing countries like Bangladesh.” These pictures draw attention to the effects of the COVID-19 pandemic such as the sale of girls, by their povertystricken families, to rich men as wives or domestic workers and to the ways in which poor women and girls experience gender-based violence given the social isolation restrictions imposed on them.

Beyond these contributions, we know that there are also gaps in research, and that this issue of GHS does not capture fully the situation of girls with disabilities, or the effects of systemic racism in health care, and in situations in which doing research is simply too dangerous for them and/or would put the lives of girls and young women at risk. And, of course, there is a gap in this issue on addressing the long term impact of the pandemic, especially on mental health, although even several months into the pandemic when the articles for this issue were being written, it was clear that we need to be addressing that echo pandemic of mental health. Now, as this issue of GHS goes to press in November 2020, daily headlines remind us of the toll this pandemic is taking on young people. Allowing for these gaps, and especially those related to risk, we note that there are many other ways that academics, NGOs, and practitioners are addressing the pandemic besides doing research right now. For example, several NGOs with whom 
we work in Montreal see their brief as being about addressing food security by delivering food hampers and making a case for fund raising to connect refugee girls, their families, and communities through technology.

As researchers and activists this is also a time to think creatively about our work with girls and for girls. In a forthcoming chapter, Claudia Mitchell, Relebohile Moletsane, and Darshan Daryanani explain their interest in the idea of ethnography at a distance as a way of minimizing risk in research during the pandemic, and, in so doing, have begun to develop an inventory of strategies for doing this that range from extending community partnerships to working more collaboratively with teachers, principals, and others who have direct contact with girls, and from forming stronger alliances with journalists so that we are not all collecting the same data to practicing what might be termed a learning-from-previous-pandemics-approach. In the AIDS pandemic in South Africa in the late 1990s and early 2000s there were delays in recognizing the gendered dynamics of the pandemic and so many young women became infected simply because service provision and campaigns failed to take into account their particular vulnerabilities. As an example, the wide-spread ABC campaigns (Abstinence, Be Faithful, Condomize) instituted by government and many NGOs failed to take account of the high rates of gender-based violence and the fact that girls and young women had little control over their own sexual choices and over what was happening to them (Mitchell and Smith 2003). Abstaining, being faithful, and using a condom were simply not options for girls and young women in situations of unwanted sex. Applying this lesson from the AIDS pandemic in the time of COVID-19, policy makers should call for a gender analysis of the situation as a starting point.

We are, of course, lacking a crystal ball to show us what the world will look like post COVID-19 and the implications of this for girls and young women. Even so, it seems clear that this pandemic is making us even more aware of the gendered gaps and what these gaps might or will mean in relation to the lives of girls and young women, ranging from what counts as essential services, to a greater recognition that ethical research with and for girls is going to be fundamentally inflected by COVID-19 for years to come. 


\section{References}

Mitchell, Claudia, Relebohile Moletsane, and Darhsan Daryanani (forthcoming). The Ethics of Risk Research in the time of COVID-19: Ethnography at a Distance in Privileging the Well-being of Girls and Young Women in the Context of Gender-Based Violence in Rural South Africa. In COVID-19: The Perspective of Sociology of Risk and Uncertainty, ed. Jens Zinn. London: Palgrave Macmillan.

Mitchell, Claudia, and Ann Smith 2003. 'Sick of AIDS': Life, Literacy and South African Youth. Culture, Health \& Sexuality: An International Journal for Research, Intervention and Care 5 (6): 513-522. https://doi. org/10.1080/13691050110149909.

UN Women Headquarters. "Issue Brief: COVID-19 and Ending Violence against Women and Girls: Digital Library: Publications." New York: UN Women. United Nations Entity for Gender Equality and the Empowerment of Women (UN Women). https://www.unwomen.org/en/digital-library/ publications/2020/04/issue-brief-covid-19-and-ending-violence-againstwomen-and-girls 
